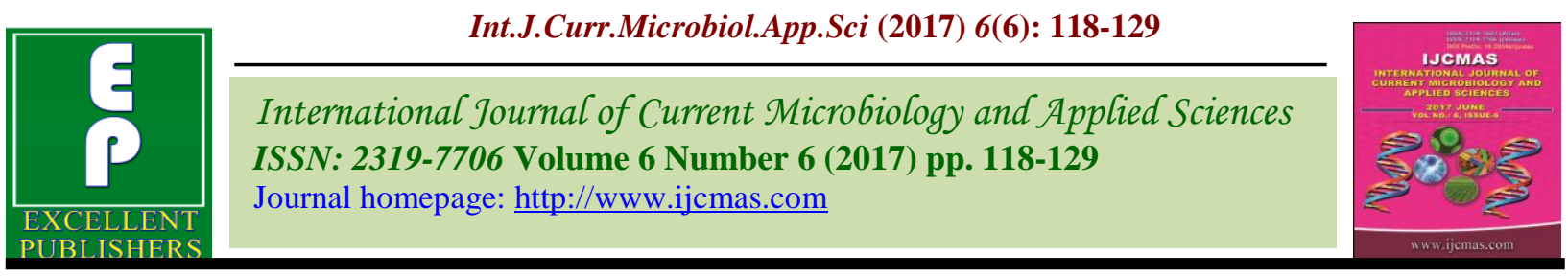

Original Research Article

https://doi.org/10.20546/ijcmas.2017.606.014

\title{
Inheritance of A Few Quality Parameters of Rice Grain (Oryza sativa L.)
}

\author{
M. Tiwari* and S. Bhattacharya \\ Department of Genetics and Plant Breeding, \\ Bidhan Chandra Krishi Viswavidyalaya, Mohanpur, West-Bengal, India \\ *Corresponding author
}

\begin{abstract}
A B S T R A C T
Keywords

The experiment was carried out with a RIL (F7) population (100 lines out of 189 lines available) raised by crossing between Gobindabhog and Satabdi. They were grown in the Regional Research Sub- Station, Sekhampur, and Nadia. Out of eleven quality parameters, kernel breadth, ratio of length and breadth after cooking, elongation ratio, aroma and

Rice, Inheritance, Quality parameters, Cooking quality, Grain characters. colour of kernel possess significant difference between two parents. Similar set of alleles for $100 \mathrm{SW}$ is present in both parents as evidenced from the fact that $85 \%$ of RILs was within the narrow range of two parental values. Like Basmati, Kernel elongation ratio after cooking of Gobindabhog can be utilized as donor parent for improving this character in other rice too. Amylose contain (AC) in both the parental genotypes is $20-15 \%$ which may be called as intermediate category. However, instead of a similar major locus of chromosome 6 (amy6) for mylase present in both parents, RILs showed significant variation ranges from $17 \%$ to $22 \%$. It is mainly due to contribution of favourable alleles of Gobindabhog present in another minor QTL, amy3, of chromosome 3. Betaine aldehyde dehydrogenase 2 (BAD2) gene is a major gene controlling aroma in Gobindabhog probably with one or two minor gene/s as evidenced from aroma analysis of RILs as well as their status of BAD2 gene. Among the hundred lines, RIL85 was selected as the best semidwarf high yielding line with higher kernel length, cooked kernel elongation ratio, low intermediate ASV, above $20 \%$ (by percentage of starch) amylose and aroma.
\end{abstract}

\section{Introduction}

Rice is one of the most important cereal crops in the world, providing $21 \%$ of the food for the world population and up to $76 \%$ calorie intake for Southeast Asian. It has become a useful model crop, largely because it has a small genome size (400 mb) compared with other major crops. Not only for smaller genome size but also for the availability of high precision genome sequencing and saturated molecular markers, rice is the target crop for several map-based gene discoveries. It has been estimated that a $40 \%$ increase in rice production by 2030 will meet the demand of the predicted world population. Increase only in rice productivity will not be sufficient as consumers' preference shifted towards specific quality parameters of rice. That's why instead of availability of several high yielding rice varieties only a few of those are accepted by the farmers. Farmers accept only those which can fetch higher market price and meet consumers' preference. So, now an ideal superior rice cultivar should have high grainyield potential with improved grain quality, nutritional value, disease resistance and stress tolerance. Quality of rice depends on the 
consumers' preference and it changes according to the region. Therefore, landraces which were adopted for a specific region by hundreds of years may be a source of alleles for quality parameters and can be utilized by the breeders for improvement of quality parameters specific for that niche. Although quality depends on the consumers' preference but mainly grain shape and a few biochemical parameters are the major determinant. These two parameters primarily control the market value of rice grain. Over the past ten years, the development of DNA markers and genome sequencing technology have led to rapid development in the mapping and cloning of genes underlying grain quality parameters of rice. Four hundred QTLs have been assigned for explaining the variation in quality parameters of rice. Thirteen of them already cloned and their role in controlling quality parameters have been ascertained by reverse genetics approach. Not all of these genes or QTLs are responsible for controlling quality parameters of a particular rice variety. Rather, it depends on the genetic background of the specific variety and its growing environment. Thus, inheritance pattern of quality parameters is more complex than it was expected. In this study, a bi-parental RIL population (F7) comprising of one hundred heterogeneous lines and fifty rice genotypes were used for assessing the quality parameters when grown in RRSS, Sekhampur farm of our university. Two parents used for developing RIL population were famous for their quality parameters and they were Gobindabhog (an aromatic Bengal landrace) and Satabdi (released in WB, only based on consumer's preference for its quality parameters). To understand the inheritance of quality parameters and role of some major QTLs controlling the parameters the present experiment was undertaken.

\section{Materials and Methods}

The experiment was carried out with a RIL (F7) population (100 lines out of 189 lines available) raised by crossing between Gobindabhog and Satabdi. They were grown in the Regional Research Sub- Station, Sekhampur, Nadia. The experimental soil was red laterite with good drainage facilities. The $\mathrm{PH}$ of soil was 5.8. Observations were recorded on different yield and quality parameters. Observations recorded from five individual plants of each lines (three replications of each line). Various primers used in the experiment were presented in table 1. Measurement of various quality parameters is given below.

\section{Cooked Kernel Elongation Ratio (CKE)}

It was measured by dividing the length of cooked rice kernel by the length of original (uncooked) kernel (Hussain et al.,, 1987).

\section{Procedure}

$50 \mathrm{ml}$ graduated centrifuge tubes were taken and $15 \mathrm{ml}$ water (initial) added. And then $5 \mathrm{gm}$ rice sample was added, it was soaked for 10 mins. It was cooked in water bath for 20 mins. (for Gobindabhog $19 \mathrm{mins}$ at $100^{\circ} \mathrm{C}$ ). The cooked rice was put on blotting paper. 10 cooked grains (intact at both ends) were selected and measured the lengths of the kernel using mm paper.

Kernel length after cooking

Elongation Ratio =

Kernel length before cooking

\section{Kernel Colour}

Kernel colour was observed visually. 


\section{Aroma}

Aroma was detected by organoleptic panel test (IRRI, 1971). In the present study, aroma was detected from naked seed (brown rice)

\section{Procedure}

$2 \mathrm{gm}$ of brown rice was taken in a test tube and then $10 \mathrm{ml}$ of distilled water was added. It was soaked for $10 \mathrm{~min}$. The rice was boiled about 30-35 min. (till the rice properly cooked), with a cotton plug on the test tube. The test tubes were cooled by running tap water or putting the test tubes in beaker containing cold water. Aroma was detected by a panel of 3 judges.

Scoring: $0=$ Absent, $1=$ Mild, $2=$ Medium, 3 $=$ Strong

\section{Amylose content}

It was estimated as per (Sadasivam and Manickam, 2008). Weighed $100 \mathrm{mg}$ of rice flour and added $1 \mathrm{ml}$ of distilled ethanol. Then $10 \mathrm{ml}$ of $1(\mathrm{~N}) \mathrm{NaOH}$ was added and kept it in a vigorously boiling water bath for 15 minutes. The volume was made up to 50 $\mathrm{ml}$ with distilled water. Then $5 \mathrm{ml}$ of the extract in a $100 \mathrm{ml}$ volumetric flask was taken and about $20 \mathrm{ml}$ of distilled water is added. Two drops of phenolphthalein was also added. To neutralize it, $0.1 \mathrm{~N} \mathrm{HCl}$ was added drop by drop until the pink colour just disappeared. After then $1 \mathrm{ml}$ of iodine reagent was added and make up the volume to $100 \mathrm{ml}$ and read the colour at $590 \mathrm{~nm}$ after waiting 30 minutes. Diluted $1 \mathrm{ml}$ of iodine reagent to 100 $\mathrm{ml}$ with distilled water for a blank. The amount of amylose present in the sample was calculate using the standard graph.

\section{Alkali spreading value}

Duplicate sets of six whole milled kernels were selected without cracks and put them in plastic petridishes. Then $10 \mathrm{ml}$ of $1.7 \% \mathrm{KOH}$ was added. The kernels were spaced in such a way that enough space should present between kernels to allow for spreading. Kept the samples undisturbed at 27-300c for $24 \mathrm{hr}$. A standard variety was used as a check. The spreading and clearing of kernels noted on a 7 point scale (Table 2) was expressed as average of six values (Little et al., 1958).

\section{Results and Discussion}

The traits and parameters for measuring quality rice grain vary across country. Here a bi-parental recombinant inbred population (RIL) comprising of one hundred lines was considered for enumerating the nineteen parameters. Other than four yield attributing parameters (first four columns), fifteen parameters as shown in Appendix 1 are main determinant for assessing quality parameters of rice in India vis-a-vis West Bengal. RIL population used in this study was available at the department of Genetics and Plant breeding which was raised by crossing between Gobindabhog and Satabdi. Two cultivars used in this study are popular for their quality parameters. Gobindabhog is famous in Gangetic alluvial soil for its aroma, taste and texture whereas Satabdi, instead of less yield advantage it was released due to higher acceptance by the consumers, mainly for grain shape and texture.

\section{Inheritance of quality and yield attributing parameters}

\section{Plant height}

Mean plant height for Gobindabhog and Satabdi was observed to be $128.67 \mathrm{~cm}$ and $101.67 \mathrm{~cm}$ respectively. The most dwarf and tallest plant height among the RILs was recorded to be $83.33 \mathrm{~cm}$ and $134 \mathrm{~cm}$ for RIL71 and RIL-53 respectively. Plant height below $110 \mathrm{~cm}$ was recorded for 53 RILs and 
above $110 \mathrm{~cm}$ for 46 RILs and it is a good fit $1: 1$ ratio as per Chi-square test $(\mathrm{p}<0.001)$. It is to mention that it had produced two discrete groups (Fig. 1). Height of any RILs was not in between $104 \mathrm{~cm}$ to $109 \mathrm{~cm}$. Therefore, result is consistent with earlier observation that semidwarf trait of rice is controlled by a single gene, which is also known as SD1 (semi dwarf 1) gene. The SD1 gene has been mapped on chromosome 5 (Cho et al., 1994) functions as the $\alpha$-subunit of GTP-binding protein (Fujisawa et al., 1999) which is insensitive to Gibberellins (GA), responsible for internode elongation. Although Plant height was neither contributing towards yield nor quality yet it was considered to check whether the population used for analysis was biased or not. As it had shown 1:1 segregation of semi dwarf and tall plant as expected for a monogenic trait, so, population used in analysis is a real unbiased population.

\section{0 seeds weight}

No significant difference of 100-seed weight was observed between Gobindabhog (2.15g) and Satabdi (2.0g). 100-seed weight of Gobindabhog, popularly known as khaschal which is readily available in Burdwan, Midnapore and other districts of West Bengal, is approximately $18-19 \mathrm{~g}$. Therefore, it is conclusively prove that Gobindabhog used in this study probably originated by field mutant. As grain shape is also longer than that of original Gobindabhog, it may be concluded that studied genotypes probably originated from the mutation of a gene which controlling both grain shape and 100 seed weight. It has been evidence by mapping analysis of earlier author that a major QTL for 100 seed weight (GW3) also located on the same place where a major locus for kernel shape GS3 is situated (Guo et al., 2009). Average 100 seeds weight of 100 RILs was recorded to be $2.21 \mathrm{~g}$. 100 seeds weight ranges from $1.23 \mathrm{~g}$ to $3.57 \mathrm{~g}$ among the RILs (Appendix table). 100 seed weight of more than $85 \%$ of RILs was within the range of two parental values. Approximately $10 \%$ of RILs showed higher 100 seed weight than that of heavier parent, Gobindabhog (Fig. 2). Based on frequency distribution pattern (Fig. 5), it can be concluded that same set of alleles for $100 \mathrm{SW}$ is present in both parents. $100 \mathrm{SW}$ of rice to be controlled by several loci located on chromosome 1, 3, 6, 8 and 9. A locus present in chromosome 3 is same for both the parents (Fg-2). So, transgressive segregation may be due to allelic difference of one or two loci other than GS3 or GW3 located on chromosome 3 .

\section{Kernel Length after Cooking (KLAC)}

No significant difference was observed for KLAC or KBAC between Gobindabhog and Satabdi. Average KLAC of 100 RILs was recorded to be $7.70 \mathrm{~mm}$ and ranges from 6.81 $\mathrm{mm}$ to $7.41 \mathrm{~mm}$. Majority of RILs were within the range between Gobindabhog and Satabdi. Surprisingly, significant difference was observed for $\mathrm{L} / \mathrm{B}$ ratio after cooking. Grain L/B ratio was higher in Satabdi but $\mathrm{KL} / \mathrm{KB}$ after cooking was higher in Gobindabhog. So like Basmati type aromatic rice, Kernel elongation ratio (KLAC/LBAC) of Gobindabhog can be utilized as donor parent for improving this character in other rice too. To understand the possible chromosomal loci responsible for elongation ratio, two markers were considered for validation using two extreme groups of RILs. These two markers were GS3 derived markers of chromosome 3 and RM339 of chromosome 8 (Ramkumar et al., 2010). GS3 marker did not amplify any polymorphic fragments between Gobindabhog and Satabdi. Thus GS3, a major determinant for kernel elongation is same for both the genotype. Probably, that's why elongation in most of the RILs is within the range of their parental value (Fig. 3). 
RM339 when used for genotyping the RILs of two extreme groups, it amplified Satabdi like alleles in four RILs with higher elongation ratio whereas reverse in RIL with lower elongation ratio (Table 3). So, locus near RM339 is not sufficient for explaining higher elongation ration in Gobindabhog (Fig. 4). Other loci present in chromosome 2, 6 and 11 (Tian et al., 2005) which were not included in this study may be responsible for higher elongation in Gobindabhog. So, RM339 is not a suitable marker for MAS when Gobindabhog will be used as a parent even it show polymorphism with other recipient parent.

\section{Amylose Content (AC)}

Higher amylose containing cultivars (>25\%) are prevalent in most of the land races (Chattopadhyay et al., 2008) of Bengal which correlates with dry, firm and separate grains of cooked rice, usually become hard after cooling. Intermediate amylose (20-25\%) rice is soft but not sticky and generally prevalent in most semi-dwarf indica cultivars. Low amylose cultivars (15-20\%) are tender, cohesive, glossy and contain nearly all temperate japonica cultivars whereas very low (less than $10 \%)$ and waxy rice $(<2 \%)$ grains are sticky. Here, both the parental genotypes are in the category of intermediate category. They contain above $20 \%$ of amylose. It is to note that percentage of amylose presented in table 4 was evaluated based on dry weight of rice flour not based on the total starch contain. As rice grain contain almost $90 \%$ or percentage of starch so percentage of amylose will be above $20 \%$ but not above $25 \%$. However, instead of little variation exists between two parents, RILs showed wide variation ranges from $17 \%$ to $22 \%$.

Table.1 Primer sequences of used SSR and functional markers

\begin{tabular}{|c|c|c|c|c|}
\hline $\begin{array}{c}\text { SSR } \\
\text { Marker }\end{array}$ & Forward primer & Reverse primer & $\begin{array}{c}\text { Chromosome } \\
\text { No. }\end{array}$ & cM \\
\cline { 1 - 3 } RM7 & TTCGCCATGAAGTCTCTCG & CCTCCCATCATTTCGTTGTT & 3 & 64 \\
\hline RM190 & CTTTGTCTATCTCAAGACAC & TTGCAGATGTTCTTCCTGATG & 6 & 7.4 \\
\hline RM253 & TCCTTCAAGAGTGCAAAACC & GCATTGTCATGTCGAAGCC & 6 & 37 \\
\cline { 1 - 3 } RM339 & GTAATCGATGCTGTGGGAAG & GAGTCATGTGATAGCCGATATG & 8 & 72.2 \\
\hline EFP & AGGCTAAACACATGCCCATCTC & \multirow{2}{*}{3} & \\
\cline { 1 - 2 } ERP & CCCAACGTTCAGAAATTAAATGTGCTG & & \\
\hline IRSP & AACAGCAGGCTGGCTTACTCTCTG & \\
\cline { 1 - 2 } IFLP & ACGCTGCCTCCAGATGCTGA & & \\
\hline
\end{tabular}

Table. 2 A 7 point scale of spreading and clearing of kernels

\begin{tabular}{|l|l|l|}
\hline Clarification & Rating & GT \\
\hline $1-2$ & Low & High $>740 \mathrm{C}$ \\
\hline $3-4$ & Low intermediate & High, intermediate (71-740C) \\
\hline $5-6$ & Intermediate & Intermediate (700C-740C) \\
\hline 7 & High & Low $<700 \mathrm{C}$ \\
\hline
\end{tabular}


Table.3 Genotyping by RM339 and phenotyping of cooked kernel elongation ratio in two parents and members of two extreme RILs

\begin{tabular}{|c|c|c|}
\hline Genotype & Kernel elongation ratio & Allele of RM339 \\
\hline RIL 7 & 1.3 & S \\
\hline RIL 22 & 1.28 & S \\
\hline RIL 28 & 1.25 & S \\
\hline RIL 6 & 1.24 & $\mathrm{G}$ \\
\hline RIL 13 & 1.23 & S \\
\hline RIL 12 & 1.22 & S \\
\hline Gobindabhog & 1.17 & $\mathrm{G}$ \\
\hline Satabdi & 1.05 & $\mathrm{~S}$ \\
\hline RIL 49 & 0.98 & $\mathrm{~S}$ \\
\hline RIL 37 & 0.98 & $\mathrm{~S}$ \\
\hline RIL 59 & 1.03 & $\mathrm{~S}$ \\
\hline RIL 53 & 1.04 & $\mathrm{~S}$ \\
\hline RIL 30 & 1.04 & $\mathrm{G}$ \\
\hline RIL 27 & 1.04 & $\mathrm{~S}$ \\
\hline RIL 29 & 1.05 & \\
\hline
\end{tabular}

Table.4 Genotyping by RM7 and phenotyping of amylose content in two parents and RILs

\begin{tabular}{|c|c|c|}
\hline GENOTYPE & AMYLOSE CONTENT (\%) & GENOTYPING (RM-7) \\
\hline RIL 100 & 21.94 & $\mathrm{G}$ \\
\hline RIL 82 & 21.16 & $\mathrm{~S}$ \\
\hline RIL 88 & 21.16 & $\mathrm{G}$ \\
\hline RIL 41 & 21.14 & $\mathrm{G}$ \\
\hline RIL 74 & 21.14 & $\mathrm{G}$ \\
\hline RIL 65 & 21.1 & $\mathrm{G}$ \\
\hline RIL 55 & 21.06 & $\mathrm{G}$ \\
\hline Gobindabhog & 20.19 & \\
\hline Satabdi & 19.82 & $\mathrm{G}$ \\
\hline RIL 31 & 17.03 & $\mathrm{G}$ \\
\hline RIL 1 & 17.07 & $\mathrm{~S}$ \\
\hline RIL 97 & 17.49 & $\mathrm{~S}$ \\
\hline RIL 80 & 17.68 & $\mathrm{G}$ \\
\hline RIL 76 & 17.72 & \\
\hline
\end{tabular}

Table.5 Single point ANOVA analysis for amylose content

\begin{tabular}{lrrrr}
\hline Groups & Count & \multicolumn{1}{c}{ Sum } & Average & Variance \\
\hline Column 1 & 7 & 144.57 & 20.65286 & 2.646557 \\
Column 2 & 5 & 91.12 & 18.224 & 2.76013 \\
\hline
\end{tabular}

\begin{tabular}{|c|c|c|c|c|c|c|}
\hline Source of Variation & $S S$ & $d f$ & $M S$ & $F$ & $P$-value & $F$ crit \\
\hline Between Groups & 17.20643 & 1 & 17.20643 & 6.391722 & 0.029964 & 4.964603 \\
\hline Within Groups & 26.91986 & 10 & 2.691986 & & & \\
\hline Total & 44.12629 & 11 & & & & \\
\hline
\end{tabular}


Fig.1 Frequency curve for plant height

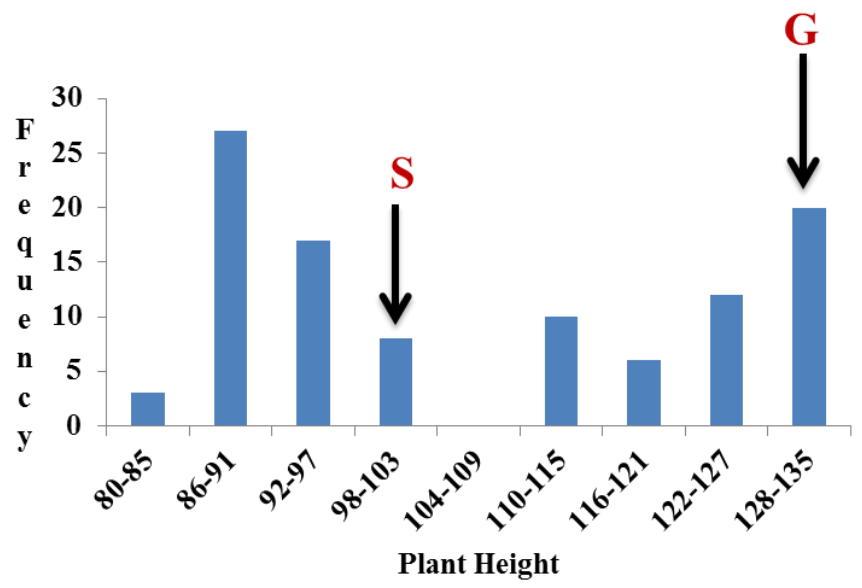

Fig.2 Frequency curve 100 seed weight

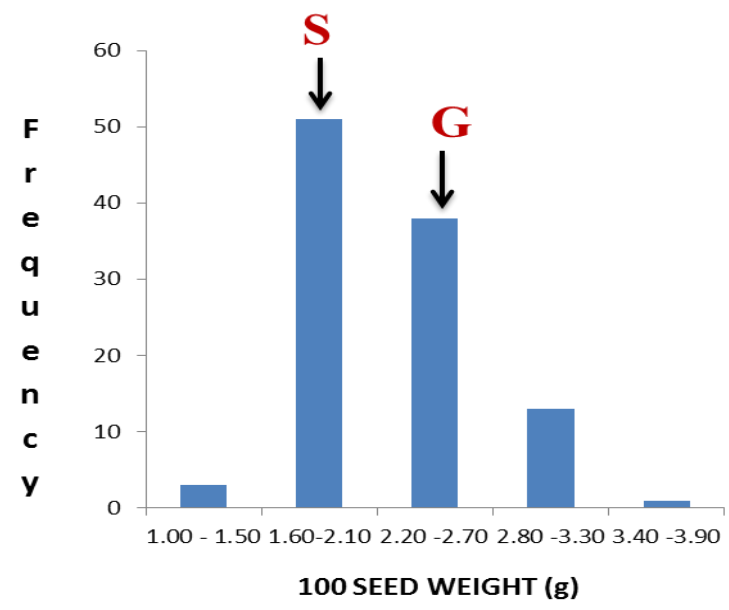

Fig.3 Frequency curve for cooked kernel elongation ratio

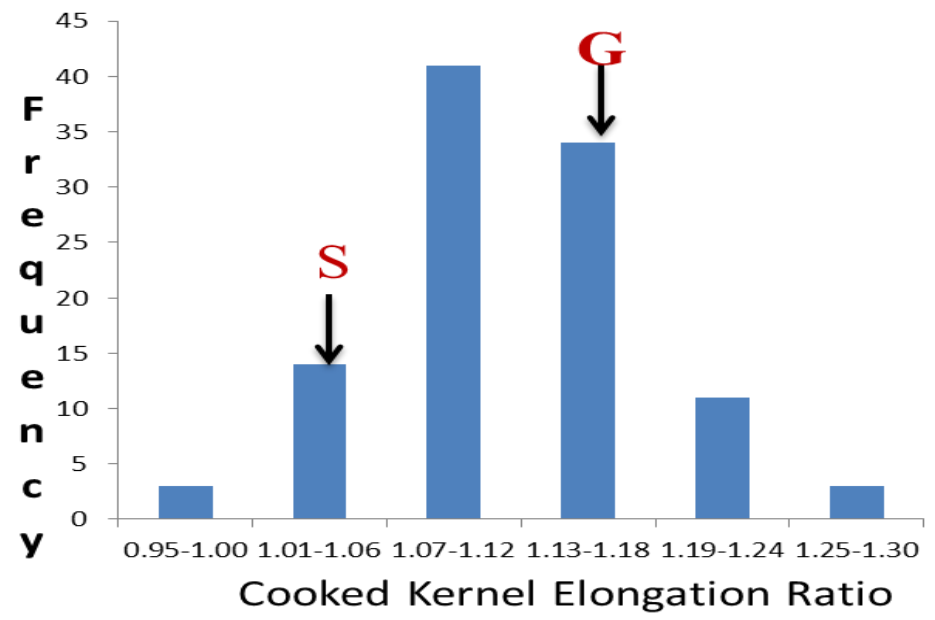


Fig.4 Agarose gel picture showing different alleles of RM339 in two parents and members of two extreme RILs (G- Gobindabhog, S- Satabdi, No.shows RIL No.)

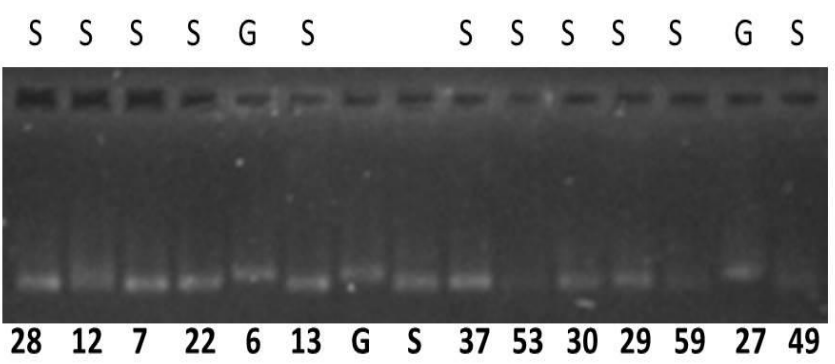

Fig.5 Frequency curve for amylose content

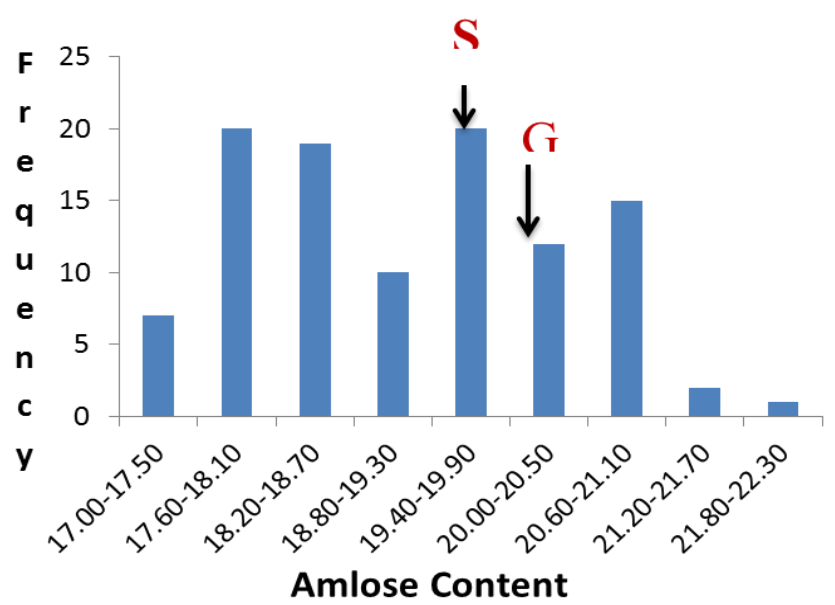

Fig.6 Agarose gel picture showing different alleles of RM7 in two parents and RILs (G- Gobindabhog, S- Satabdi, No-shows RIL No.)

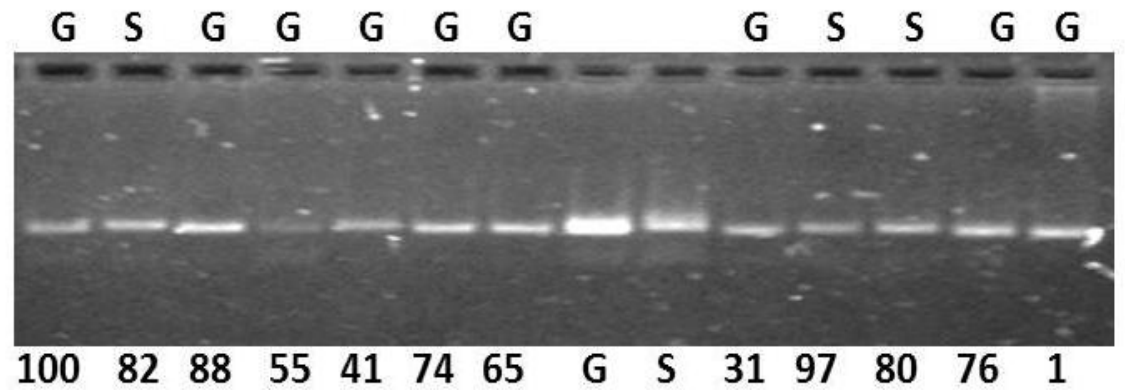


Fig.7 Frequency curve for alkali spreading value

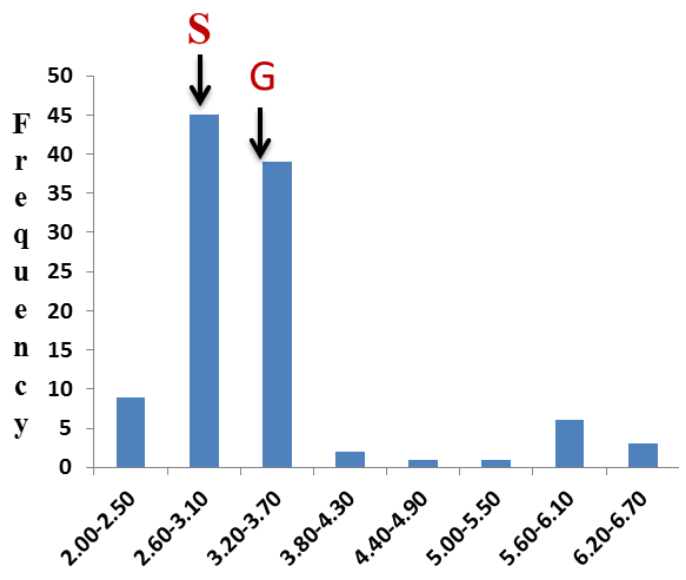

Alkali Spread Value

Fig.8 Frequency curve for aroma

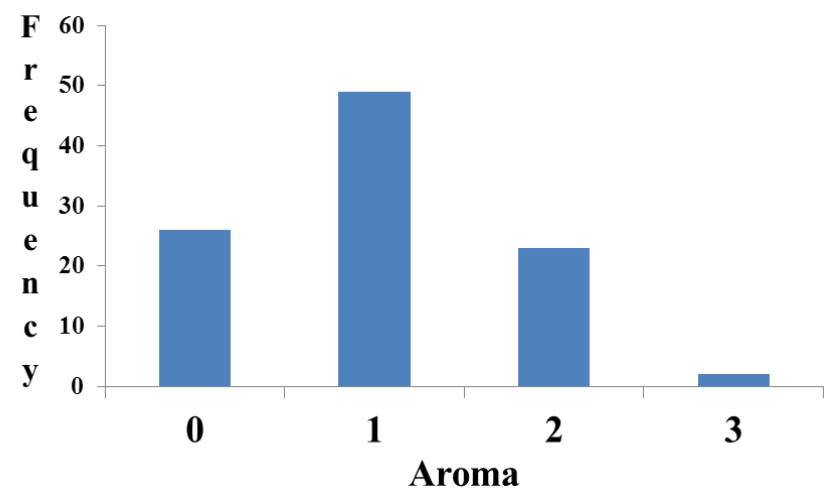

Fig.9 Agarose gel picture showing different alleles of multiplexmarker (EAP, ESP, IFAP, INSP) in two parents and RILs. (G- Gobindabhog, S- Satabdi, (Parent blue colour) No.shows RIL No.)

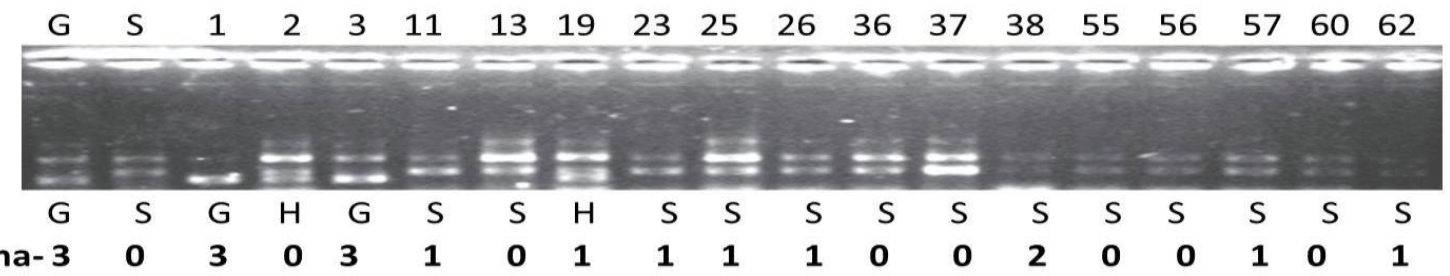


Fig.10 Frquency curve for kernel colour

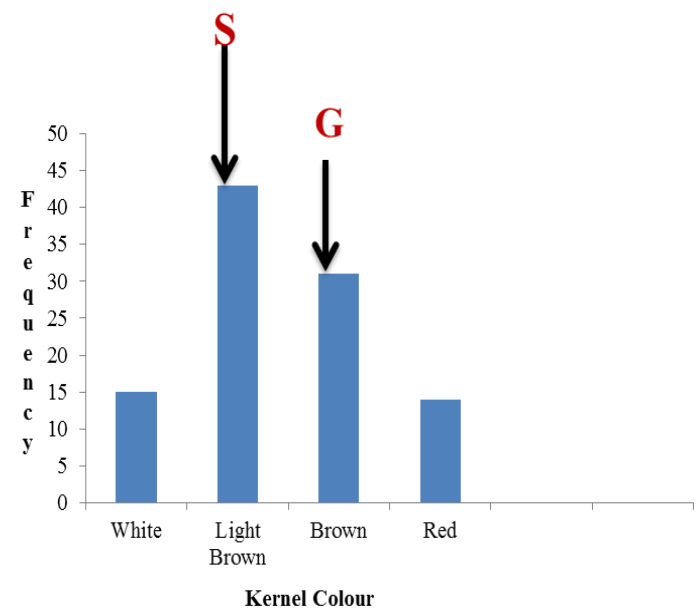

Variation is continuous and skewed towards low amylose contain. So, more than one loci is influencing the amylose contain. As it showed a large amount of transgressive segregants, so two parents probably contain diverse set of alleles or some epistatic interaction is controlling the amylose contain. A major QTL for amylose contain, amy6, which explain more than $70 \%$ of the total variation (Aluko et al., 2004, He et al., 1999, Tan et al., 1999, Lanceras et al., 2000, Septiningsh et al., 2003) is located in between RM190 and RM253. This locus is also assigned as waxy (wx) locus of rice. Both the markers, RM190 and RM253 did not show any polymorphism between two parents. Probably that is one of the reasons that both parents contain approximately same amount of amylose.

So another marker, RM7, linked with the other locus, amy3, of chromosome 3 (He et al., 1999; and Lanceras et al., 2000) was considered and found polymorphism. This polymorphic SSR was considered for genotyping of two extreme group members comprising of twelve RILs. All seven higher amylose containing RILs amplified a Gobindabhog type allele, as expected, except RIL88. On the other hand, low Amylose containing RILs amplified Satabdi allele except RIL31. As per single point ANOVA analysis, mean amylose contains of RILs with gobindabhog and Satabdi allele was 20.65\% and $18.22 \%$ respectively. This difference in amylose contains between two groups due to presence or absence of RM7 alleles is statistically significant (Table 5). Therefore, it can be concluded that amy3 locus of Gobindabhog has significant positive contribution than that of Satabdi and RM7 can be used for marker assisted breeding for improvement of amylose in rice.

\section{Alkali Spreading Value (ASV)}

Alkali spreading value of whole kernel milled rice in contact with dilute alkali is a measure of gelatinization temperature and partly associated with amylose content of starch. Low intermediate alkali-spreading score was predominant as 80 of the RIL which scored between 3-4. RIL-63, RIL-30, RIL-46, RIL26, RIL-27, RIL-60, RIL-61, RIL-62, RIL-31 and RIL-29 have shown 5-6 ASV scale which indicates intermediate gelatinization temperature (700C-740C). It is evident from the figure 7 that a common major gene in both the parents is responsible for ASV with some modifier gene action since two major groups 
were formed but a few transgressive segregants were also observed.

\section{Aroma}

Small grain aromatic rice that has long been preferred in eastern India now become popular in middle east, Australia, Europe. Among the several chemical constituents that are important for aroma of cooked rice, 2acetyl 1-pyroline (AP) has been shown to be the most important component in small or large grain aromatic rice (Lorieux et al., 1996). It has now been established that single recessive gene $(f g r)$ is responsible for aroma as determined by the level of AP. Accumulation of AP increases in rice due to loss of an enzyme betaine aldehyde dehydrogenase 2 (BAD2). AP is a substrate for the enzyme BAD2. Thus loss of function of BAD2 gene causes increase deposition of AP vis-à-vis aroma. In this study, four categories of RILs were observed as per degree of aroma those were 0,1,2,3 (Fig. 8). Two parents showed either zero or three. Therefore it can be concluded that more than one gene is responsible for aroma in Gobindabhog. Probably, in addition of BAD2 gene, one or two minor genes are also responsible. When, a multiplex marker considering the eight base pair deletion region of BAD2 gene was used for validation of a twenty random RILs it was clearly established the presence of a minor gene other than BAD2 gene. RIL19, 23, 25 did not contain the defective BAD2 gene (Fig. 9) but aroma was found in their grain although much less than that of Gobindabhog. Out of one hundred RILs, aroma was absent in 25 RILs, 49 RILs observed to have mild aroma, 23 RILs showed medium aroma and only two RILs showed strong aroma like Gobindabhog. It is also to prove that several lines with BAD2 gene did not show stronger aroma like Gobindabhog. So, BAD2 gene is a major gene controlling aroma in Gobindabhog probably with one or two minor gene/s.

\section{Kernel colour}

The outer bran layer of the grain and embryo (germ) is what gives rice its color and can vary from light yellow to red to dark purplish black. In this study, four categories of Kernel color appeared in RILs and they were white, light brown, brown and red, although colour for Gobindabhog and Satabdi was observed to be brown and light brown respectively. Two extreme and additional colors like white (in 15 RILs) and red (in 14 RILs) were appeared in RILs almost in equal ratio (Fig. 10). Therefore, more than three loci with epistatic gene actions are probably controlling the kernel colour of two parents included in this study.

\section{References}

Aluko, G. (2004). QTL mapping of grain quality traits from the interspecific cross Oryzasativa x O. glaberrima. Theor. Appl. Genet.109: 630-639

Aluko, G., Martinez, C., Tohme, J., Castano, C., Bergman C. and Oard J. H. (2004): QTL mapping of grain quality traits from the interspecific cross Oryza sativa $\mathrm{X} \mathrm{O}$. glaberrima. Theor. Appl. Genet.109: 630639.

Chattopadhyay T, Biswas T, Chatterjee M; Mandal N, Bhattacharyya S (2008) Biochemical and SSR marker based characterization of some Bengal landraces of rice suffixed with 'sail' in their name. Indian J Genet and Pl Breeding 68:15-20.

Cho, Y. G., Eun, M. Y.,.Mccouch, S. R. and Chae, Y. A. (1994).The semidwarf gene, sd-1, of rice (Oryza sativa L). 2. Molecular mapping and marker-assisted selection. Theor. Appl. Genet. 89:54-59.

Fujisawa, Y., Kato, T., Ohki, S., Ishikawa, A., Kitano, H. and Sasaki, T.(1999). Suppression of the heterotrimeric $\mathrm{G}$ protein causes abnormal morphology, including dwarfism, in rice. Proc. Natl. Acad. Sci. USA.96:7575-7580. 
Guo, L. (2009) Genetic analysis and fine mapping of two genes for grain shape and weight in rice. J. Integr. Plant Biol. 51: 45-51.

Guo, L., Ma, L., Jiang, H., Zeng, D., Hu, J. and $\mathrm{Wu}$, L. (2009). Genetic analysis and fine mapping of two genes for grain shape and weight in rice. J. Integr. Plant Biol.51:4551.

He, P., Li, S.G., Qian, Q., Ma, Y.Q., Li, J. Z., Wang, W.M., Chen, Y., Zhu, L. H., (1999) Genetic analysis of rice grain quality. TheorAppl Genet. 98:502-508

Hussain, A. A., Maurya, D. M. and Vaish, C. P. (1987). Studies on quality status of indigenous upland rice. Indian J. Genetics., 47:145-152.

International Rice Research Institute (1971). Annual Report for 1970. Los Banos, Laguna, Phillipines. Pp-265.

Lanceras, J. C., Huang, Z. L., Naivikul, O., Vanavichit, A., Ruanjaichon, V. and Tragoonrung, S. (2000). Mapping of genes for cooking and eating qualities in Thai Jasmine rice (KDML105).DNA Res. 7:93101

Lanceras, J. C., Huang, Z. L., Naivikul, O., Vanavichit, A., Ruanjaichon, V. and Tragoonrung, S. (2000). Mapping of genes for cooking and eating qualities in Thai Jasmine rice (KDML105).DNA Res.7: 93101.

Little, R. R., Hilder, G. B. and Dausson, E. H. (1958). Differential effect of dilute alkali on 25 varieties of milled white rice.Cereal Chem. 35: 111-126.

Lorieux, M., Petrov, M., Huang, N., Guiderdoni, E. and Ghesquiere, A. (1996). Aroma in rice: Genetic analysis of a quantitative trait. Theor. Appl. Genet., 93: 1145-1151.
Ramkumar, G., Sivaranjani,A.K.P., Mamish K. Panday, Sakthivel, K. (2010). Development of a PCR based SNP marker system for effective seletion of kernel length and kernel elongation in rice. Mol.Breeding.26: 735-740.

Sadasivam, S. and Manickam, A. (2008). In carbohydrates.Biochemical Methods.Pp 1011.Acga, C., Ismanizan, I., Mohamad, O., and Habibuddin, H. (2012). Simple and Rapid Molecular Techniques for Identification of Amylose Levels in Rice Varieties. Int. J. Mol. Sci.13: 6156-6166.

Septiningsih, E. M., Trijatmiko, K. R., Moeljopawiro, S., McCouch, S. R., (2003) Identification of quantitative trait loci for grain quality in an advanced backcross population derived from the Oryza sativa variety IR64 and the wild relative $O$. rufipogon.TheorAppl Genet.107:14331441.

Septiningsih, E. M., Trijatmiko, K. R., Moeljopawiro, S. and McCouch S. R. (2003). Identification of quantitative trait loci for grain quality in an advanced backcross population derived from the Oryza sativa variety IR64 and the wild relative $O$. rufipogon. Theoretical and Applied Genetics.107: 1433-1441.

Tan, Y. F., Li,J. X., Yu, S. B., Xing, Y. Z., Xu, C. G., Zhang, Q. F. (1999) The three important traits for cooking and eating qualities of rice grain are controlled by a single locus. TheorAppl Genet.99:642-648.

Tian, R., Jiang, G. H., Shen, L. H., Wang, L.Q., and He, Y.Q. (2005). Mapping quantitative trait loci underlying the cooking and eating quality of rice using a DH population. Mol Breed15:117-124.

\section{How to cite this article:}

Tiwari, M. and Bhattacharya, S. 2017. Inheritance of A Few Quality Parameters of Rice Grain (Oryza sativa L.). Int.J.Curr.Microbiol.App.Sci. 6(6): 118-129. doi: https://doi.org/10.20546/ijcmas.2017.606.014 